\title{
Effects of Aquatic Therapy on Pain in Children with Profound Intellectual and Multiple Disabilities-A Prospective Observational Study
}

\author{
Michal Nissim, Yaaser Sanduka \\ The David Yellin Academic College of Education, Jerusalem, Israel \\ Email: Michal.beren@gmail.com,nadeem@dyellin.ac.il
}

How to cite this paper: Nissim, M., \& Sanduka, Y. (2021). Effects of Aquatic Therapy on Pain in Children with Profound Intellectual and Multiple Disabilities-A Prospective Observational Study. Creative Education, 12, 1438-1444. https://doi.org/10.4236/ce.2021.127109

Received: May 23, 2021

Accepted: July 2, 2021

Published: July 5, 2021

Copyright ( 2021 by author(s) and Scientific Research Publishing Inc. This work is licensed under the Creative Commons Attribution International License (CC BY 4.0).

http://creativecommons.org/licenses/by/4.0/

\begin{abstract}
Background: Children with profound intellectual and multiple disabilities are at risk of pain. Aquatic-therapy is a pain relief treatment. There is no data concerning the effect of aquatic-therapy on pain among this population. The study reports on the effect of aquatic-therapy on pain-related behaviours among children with profound intellectual disability. Method: Fifteen caregivers and 39 children with profound intellectual and multiple disabilities (age: 4 - 18 years) participated in this prospective observational monocentric study. All children participated in a weekly 30 -minute aquatic-therapy session. The Non-Communicating-Children's Pain-Checklist-PostoperativeVersion (NCCPC-PV) was used. Data were collected four times: twice up to two hours after an aquatic-therapy session and twice at times not following an aquatic-therapy session. Results: Results indicate a significant difference between the NCCPC-PV score for up to two hours after aquatic-therapy and the NCCPC-PV mean score when not following aquatic-therapy $(\mathrm{t}=3.784, p<$ $0.01)$. Conclusions: This is an initial evidence that aquatic-therapy helps reduce pain for children with profound intellectual and multiple disabilities.
\end{abstract}

\section{Keywords}

Aquatic Therapy, Halliwick, Hydrotherapy, Profound Intellectual and Multiple Disabilities, Pain

\section{Introduction}

Children with profound intellectual and multiple disabilities are children with profound intellectual disabilities (IQ $<20$ ), profound neuromotor dysfunctions and sometimes with sensory impairments. These children might have neither an 
apparent understanding of verbal language nor a symbolic interaction with objects (Nakken \& Vlaskamp, 2007). These children are dependent on support from others in most aspects of their daily needs such as communication (Maes et al., 2007).

Due to their motor disabilities and general health complications, these children are at risk of pain-related medical conditions (Breau et al., 2002, 2003; Cascella et al., 2019). Severe spasticity may lead to contractures and joint dislocations, both of which are risk factors for secondary health complications such as pain (Hill \& Goldsmith, 2009). Children with profound intellectual and multiple disabilities frequently have general health conditions associated with pain, such as seizure disorders, tube feeding and gastroesophageal reflux disease (Hogg, 1992; Böhmer et al., 1999; Zijlstra \& Vlaskamp, 2005). As a result, daily care activities such as dressing or diaper changing might be painful because of the movement and exertion involved (Bodfish et al., 2006; Zernikow et al., 2012).

Aquatic therapy is a common pain relief treatment for some painful clinical conditions (Kamioka et al., 2010; Mooventhan \& Nivethitha, 2014; Macías-Hernández et al., 2015). The therapeutic effects of aquatic therapy rely on the hydrodynamic properties of water (such as buoyancy, relative density, resistance, viscosity, turbulence, and hydrostatic pressure) (Nissim et al., 2019).

Aquatic therapy was found to be a pain relief treatment among people with fibromyalgia (Assis et al., 2006), multiple sclerosis (Castro-Sanchez et al., 2012) and neurologic or musculoskeletal disease (Hall et al., 2008). However, so far, there is no data from clinical trials or real life concerning the effect of aquatic therapy on pain among children with profound intellectual and multiple disabilities. In the current study we report on the effect of aquatic therapy on pain-related behaviours during daily care activities among children with profound intellectual and multiple disabilities.

\section{Method}

\subsection{Participants}

Fifteen caregivers provided informed written consent to participate in the study. Forty-one children with a profound intellectual disability (IQ below 25 or a developmental level up to 24 months) in combination with motor and/or sensory disabilities were selected. Two children dropped out since they could not participate in the aquatic therapy during the experiment time. This left a total of 39 children with profound intellectual and multiple disabilities (19 male and $20 \mathrm{fe}-$ male) aged between 4 and 18 years (with a mean age of 8.82 years). The children's characteristics can be seen in Table 1 .

\subsection{Design}

This prospective observational monocentric study was approved by the Chief Scientist of the Israeli Ministry of Education and by the Ethics Committee of David Yellin Academic College of Education. All the children in this study 
Table 1. Characteristics of the participants.

\begin{tabular}{cc}
\hline Variable & Frequency N (\%) \\
\hline Upper limb physical impairment & $22(56.4 \%)$ \\
Lower limb physical impairment & $29(74.4 \%)$ \\
Deformation & $29(74.4 \%)$ \\
Visual impairment & $15(38.5 \%)$ \\
Epilepsy & $13(33.3 \%)$ \\
Gastroesophageal reflux & $25(64.1 \%)$ \\
Medications & $15(38.5 \%)$ \\
\hline
\end{tabular}

participated in a weekly 30-minute aquatic therapy session between January and March 2020. During the aquatic therapy sessions, the Halliwick method was used. The Halliwick approach is a popular aquatic therapy technique used mainly with the paediatric population and with persons with neurological problems (Barker et al., 2014; Hou, Wan, \& Li, 2010). The Halliwick method treatment uses fluid and mechanical properties of water and is based on postural control by mobilizing and controlling body parts through the "Ten Point Program" (for more information about the Hallwick method please see Gurpinar et al., 2020). Data were collected at school during routine daily care activities (dressing or diaper changing) by the caregivers. Data were collected four times during the study period: twice up to two hours after an aquatic therapy session, conducted by qualified hydrotherapists and twice at corresponding times not following an aquatic therapy session. That is, data for times not following aquatic therapy session was collected at the same time of day the data after the aquatic therapy session was collected (aquatic therapy sessions take place on Wednesdays during school between 8:00 am to 12:00 pm, and thus the data was collected twice on Wednesdays between 10:00 am to 14:00 pm. Data for times not following aquatic therapy sessions was collected at the same time of day not on Wednesdays).

\subsection{Measures}

The Non-Communicating Children's Pain Checklist-Postoperative Version (NCCPC-PV) was selected for this study. The NCCPC-PV was designed to be used for children who are unable to speak because of cognitive (mental/ intellectual/developmental) impairments or disabilities. The NCCPC-PV was designed to be used without training by parents, caregivers, or by other adults who are not familiar with a specific child. It contains six of the seven subscales of the original version (vocal, social, facial, activity, body and limbs, physiological) (Breau et al., 2002). The Eating-Sleeping subscale of the original version was not included in the current study. Caregivers indicated how often each item was observed during dressing or diaper changing (not at all: 0 , just a little: 1 , fairly often: 2 , very often: 3 ). Scores for all items were summed to create total scores. 


\subsection{Data Analysis}

We calculated NCCPC-PV mean scores for two conditions: the NCCPC-PV mean score for the two times up to two hours after an aquatic therapy session and the NCCPC-PV mean score for the two times following an aquatic therapy session. For comparing the NCCPC-PV mean scores, we used a paired sample $\mathrm{t}$-test. Since there was a significant difference, we added Cohen's $\mathrm{d}$ for evaluation of meaningfulness. Significance was set at a level of $<0.05$. For statistical analysis, we used SPSS Statistics 25.

\section{Results}

We included 39 children with profound intellectual and multiple disabilities into this prospective observational study.

In Figure 1 we can observe the statistically significant difference between NCCPC-PV mean score for up to two hours after aquatic therapy and NCCPC-PV mean score for times not following aquatic therapy $(t=3.784, p<$ $0.01)$ with large effect sizes $(d=0.8773)$.

\section{Discussion}

To our knowledge, this is thus far the first report on the effect of aquatic therapy on pain among children with profound intellectual and multiple disabilities. In our study, there were significant differences between the NCCPC-PV mean score for up to two hours after aquatic therapy and the NCCPC-PV mean score not following aquatic therapy. These findings are in line with previous studies that found a positive effect of aquatic therapy on pain relief in people with musculoskeletal

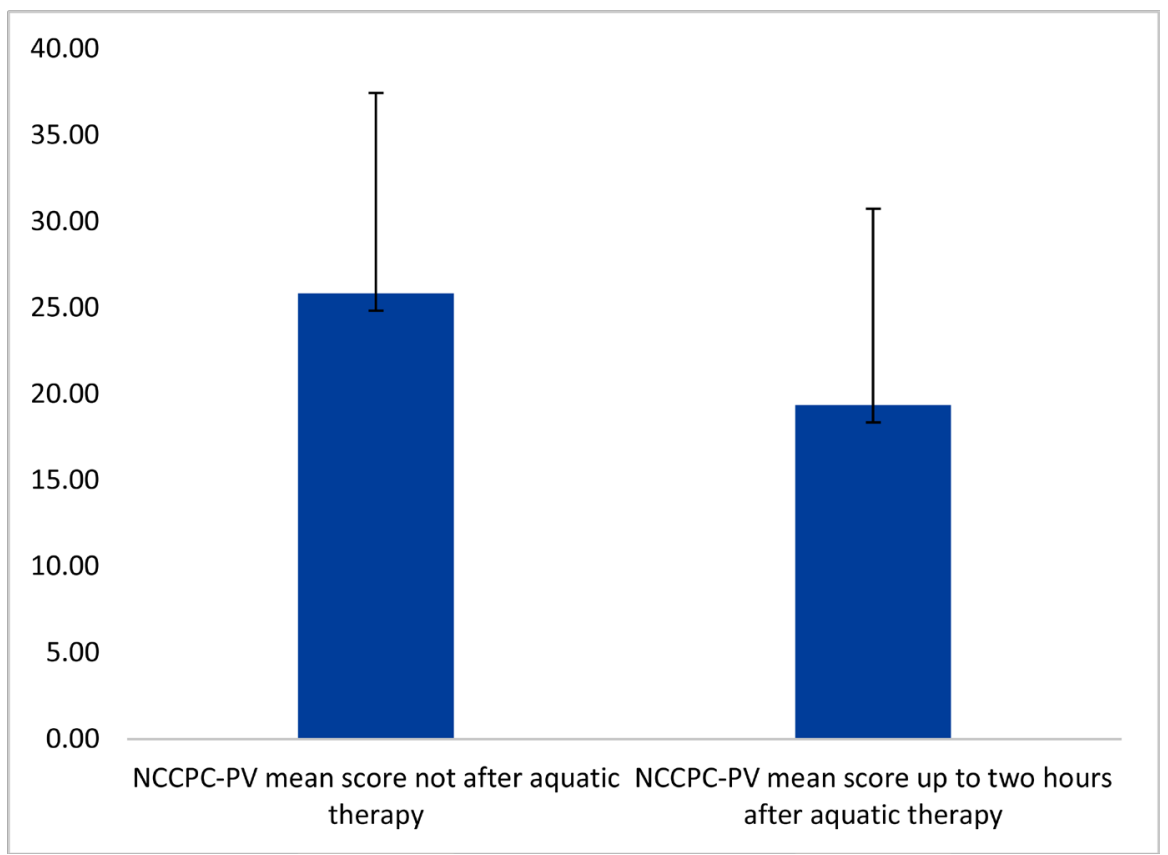

Figure 1. Difference between NCCPC-PV mean score up to two hours after aquatic therapy and NCCPC-PV mean score not after aquatic therapy $(\mathrm{t}=3.784, p<0.01)$. 
conditions (Baena-Beato et al., 2014; Castro-Sanchez et al., 2012; Mannerkorpi et al., 2009); our study expands the scope to children with profound intellectual and multiple disabilities. Children with profound intellectual and multiple disabilities are at risk of pain (Breau et al., 2002, 2003; Cascella et al., 2019), especially during daily care activities such as dressing or diaper changing (Bodfish et al., 2006; Zernikow et al., 2012). Finding an intervention program that might decrease pain levels during everyday activities is crucial. Controlling pain via an intervention programme, such as aquatic therapy, might be beneficial for a large range of conditions, among them an increase in the children's availability for learning and a better ability to withstand dental care treatments. We believe, therefore, that educators, medical and para-medical experts could find our results interesting for helping in reducing pain for children with profound intellectual and multiple disabilities.

\section{Limitations}

There are several limitations to this observational study that should be acknowledged. First, intervention duration effect on pain is still unknown. Second, the small sample size of the study prevents further sub-analyses, such as examination of the effect of participants' characteristics (for example: upper/lower limb physical impairment, deformation, gastroesophageal reflux) on the results. Finally, assessing pain of children with profound intellectual and multiple disabilities who are unable to self-report their pain, since they lack the capacity to verbally communicate is very complex and challenging (Carter, et al., 2017; Carter et al., 2016). Aquatic therapy's effect on pain should not be based on the caregiver's assessment alone, but also on objective measurements of pain. Future studies are needed to investigate these factors.

\section{Conclusion}

In conclusion, the current study provides first evidence that aquatic therapy may help reduce the pain for children with profound intellectual and multiple disabilities during everyday activities.

\section{Acknowledgements}

The authors would like to thank AL-BAKRIEH SCHOOL for its cooperation.

\section{Conflicts of Interest}

The authors declare no conflicts of interest regarding the publication of this paper.

\section{References}

Assis, M. R., Silva, L. E., Alves, A. M., Pessanha, A. P., Valim, V., Feldman, D., Neto, T. L., \& Natour, J. (2006). A Randomized Controlled Trial of Deep Water Running: Clinical Effectiveness of Aquatic Exercise to Treat Fibromyalgia. Arthritis and Rheumatism, 55, 57-65. https://doi.org/10.1002/art.21693 
Baena-Beato, P. Á., Artero, E. G., Arroyo-Morales, M., Robles-Fuentes, A., Gatto-Cardia, M. C., \& Delgado-Fernández, M. (2014). Aquatic Therapy Improves Pain, Disability, Quality of Life, Body Composition and Fitness in Sedentary Adults with Chronic Low Back Pain. A Controlled Clinical Trial. Clinical Rehabilitation, 28, 350-360. https://doi.org/10.1177/0269215513504943

Barker, A. L., Talevski, J., Morello, R. T., Brand, C. A., Rahmann, A. E., \& Urquhart, D. M. (2014). Effectiveness of Aquatic Exercise for Musculoskeletal Conditions: A Meta-Analysis. Archives of Physical Medicine and Rehabilitation, 95, 1776-1786. https://doi.org/10.1016/j.apmr.2014.04.005

Bodfish, J. W., Harper, V. N., Deacon, J., Deacon, J. R., \& Symons, F. J. (2006). Issues in Pain Assessment for Adults with Mental Retardation: From Research to Practice. In T. F. Oberlander, \& F. J. Symons (Eds.), Pain in Developmental Disabilities (pp. 173-192). Washington DC: Paul H. Brookes.

Böhmer, C. J., Niezen-de Boer, M. C., Klinkenberg-Knol, E. C., Devillé, W. L., Nadorp, J. H., \& Meuwissen, S. G. (1999). The Prevalence of Gastroesophageal Reflux Disease in Institutionalized Intellectually Disabled Individuals. The American Journal of Gastroenterology, 94, 804-810. https://doi.org/10.1111/j.1572-0241.1999.00854.x

Breau, L. M., Camfield, C. S., McGrath, P. J., \& Finley, G. A. (2003). The Incidence of Pain in Children with Severe Cognitive Impairments. Archives of Pediatrics \& Adolescent Medicine, 157, 1219-1226. https://doi.org/10.1001/archpedi.157.12.1219

Breau, L. M., Finley, G. A., McGrath, P. J., \& Camfield, C. S. (2002). Validation of the Non-Communicating Children's Pain Checklist-Postoperative Version. Anesthesiology, 96, 528-535. https://doi.org/10.1097/00000542-200203000-00004

Carter, B., Arnott, J., Simons, J., \& Bray, L. (2017). Developing a Sense of Knowing and Acquiring the Skills to Manage Pain in Children with Profound Cognitive Impairments: Mothers' Perspectives. Pain Research \& Management, 2017, Article ID: 2514920. https://doi.org/10.1097/00000542-200203000-00004

Carter, B., Simons, J., Bray, L., \& Arnott, J. (2016). Navigating Uncertainty: Health Professionals' Knowledge, Skill, and Confidence in Assessing and Managing Pain in Children with Profound Cognitive Impairment. Pain Research \& Management, 2016, Article ID: 8617182. https://doi.org/10.1155/2016/8617182

Cascella, M., Bimonte, S., Saettini, F., \& Muzio, M. R. (2019). The Challenge of Pain Assessment in Children with Cognitive Disabilities: Features and Clinical Applicability of Different Observational Tools. Journal of Paediatrics and Child Health, 55, 129-135. https://doi.org/10.1111/jpc. 14230

Castro-Sanchez, A. M., Matarán-Peñarrocha, G. A., Lara-Palomo, I., Saavedra-Hernández, M., Arroyo-Morales, M., \& Moreno-Lorenzo, C. (2012). Hydrotherapy for the Treatment of Pain in People with Multiple Sclerosis: A Randomized Controlled Trial. Evidence-Based Complementary and Alternative Medicine: eCAM, 2012, Article ID: 473963. https://doi.org/10.1155/2012/473963

Gurpinar, B., Kara, B., \& Idiman, E. (2020). Effects of Aquatic Exercises on Postural Control and Hand Function in Multiple Sclerosis: Halliwick versus Aquatic Plyometric Exercises: A Randomised Trial. Journal of Musculoskeletal \& Neuronal Interactions, 20, 249-255.

Hall, J., Swinkels, A., Briddon, J., \& McCabe, C. S. (2008). Does Aquatic Exercise Relieve Pain in Adults with Neurologic or Musculoskeletal Disease? A Systematic Review and Meta-Analysis of Randomized Controlled Trials. Archives of Physical Medicine and Rehabilitation, 89, 873-883. https://doi.org/10.1016/j.apmr.2007.09.054

Hill, S., \& Goldsmith, L. (2009). Mobility, Posture and Comfort. In J. Pawlyn, \& S. 
Carnaby (Eds.), Profound Intellectual and Multiple Disabilities: Nursing Complex Needs (pp. 328-347). London: Wiley-Blackwell Publishers.

https://doi.org/10.1002/9781444301526.ch17

Hogg, J. (1992). The Administration of Psychotropic and Anticonvulsant Drugs to Children with Profound Intellectual Disability and Multiple Impairments. Journal of Intellectual Disability Research: JIDR, 36, 473-488. https://doi.org/10.1111/j.1365-2788.1992.tb00567.x

Hou, X., Wan, Y., \& Li, C. (2010). The Effect of Halliwick Technique on the Gait of School Age Children with Spastic Cerebral Palsy. Chinese Journal of Rehabilitation Medicine, 25, 870-874.

Kamioka, H., Tsutani, K., Okuizumi, H., Mutoh, Y., Ohta, M., Handa, S., Okada, S., Kitayuguchi, J., Kamada, M., Shiozawa, N., \& Honda, T. (2010). Effectiveness of Aquatic Exercise and Balneotherapy: A Summary of Systematic Reviews Based on Randomized Controlled Trials of Water Immersion Therapies. Journal of Epidemiology, 20, 2-12. https://doi.org/10.2188/jea.JE20090030

Macías-Hernández, S. I., Vázquez-Torres, L., Morones-Alba, J. D., Coronado-Zarco, R., de Los Angeles Soria-Bastida, M., Cruz-Medina, E., \& Nava-Bringas, T. I. (2015). Water-Based Tai Chi: Theoretical Benefits in Musculoskeletal Diseases. Current Evidence. Journal of Exercise Rehabilitation, 11, 120-124. https://doi.org/10.12965/jer.150207

Maes, B., Lambrechts, G., Hostyn, I., \& Petry, K. (2007). Quality-Enhancing Interventions for People with Profound Intellectual and Multiple Disabilities: A Review of the Empirical Research Literature. Journal of Intellectual \& Developmental Disability, 32, 163-178. https://doi.org/10.1080/13668250701549427

Mannerkorpi, K., Nordeman, L., Ericsson, A., Arndorw, M., \& GAU Study Group (2009). Pool Exercise for Patients with Fibromyalgia or Chronic Widespread Pain: A Randomized Controlled Trial and Subgroup Analyses. Journal of Rehabilitation Medicine, 41, 751-760. https://doi.org/10.2340/16501977-0409

Mooventhan, A., \& Nivethitha, L. (2014). Scientific Evidence-Based Effects of Hydrotherapy on Various Systems of the Body. North American Journal of Medical Sciences, 6, 199-209. https://doi.org/10.4103/1947-2714.132935

Nakken, H., \& Vlaskamp, C. (2007). A Need for a Taxonomy for Profound Intellectual and Multiple Disabilities. Journal of Policy and Practice in intellectual Disabilities, 4, 83-87. https://doi.org/10.1111/j.1741-1130.2007.00104.x

Nissim, M., Hutzler, Y., \& Goldstein, A. (2019). A Walk on Water: Comparing the Influence of Ai Chi and Tai Chi on Fall Risk and Verbal Working Memory in Ageing People with Intellectual Disabilities-A Randomised Controlled Trial. Journal of Intellectual Disability Research: JIDR, 63, 603-613. https://doi.org/10.1111/jir.12602

Zernikow, B., Wager, J., Hechler, T., Hasan, C., Rohr, U., Dobe, M., Meyer, A., Hübner-Möhler, B., Wamsler, C., \& Blankenburg, M. (2012). Characteristics of Highly Impaired Children with Severe Chronic Pain: A 5-Year Retrospective Study on 2249 Pediatric Pain Patients. BMC Pediatrics, 12, 54. https://doi.org/10.1186/1471-2431-12-54

Zijlstra, H. P., \& Vlaskamp, C. (2005). The Impact of Medical Conditions on the Support of Children with Profound Intellectual and Multiple Disabilities. Journal of Applied Research in Intellectual Disabilities, 18, 151-161. https://doi.org/10.1111/j.1468-3148.2005.00244.x 